\title{
Diabetes, Inflammation, Proinflammatory Cytokines, and Diabetic Nephropathy
}

\author{
Juan F. Navarro ${ }^{1,2,3, *}$ and Carmen Mora ${ }^{2,3}$ \\ ${ }^{1}$ Nephrology Service, University Hospital Nuestra Señora de Candelaria, Santa Cruz \\ de Tenerife, Spain; ${ }^{2}$ Canarian Institute for Biomedical Research, University Hospital \\ Nuestra Señora de Candelaria, Santa Cruz de Tenerife, Spain; ${ }^{3}$ Spanish National \\ Research Council, Madrid \\ E-mail: nnavgon@gobiernodecanarias.org
}

Received June 19, 2006; Revised July 12, 2006; Accepted July 27, 2006; Published August 9, 2006

Diabetes and its complications have become a public health problem. Diabetic nephropathy is the main cause of renal failure. In spite of our higher knowledge on this complication, the intimate mechanisms leading to the development and progression of renal injury are not yet fully known. Activated innate immunity and inflammation are relevant factors in the pathogenesis of diabetes. Moreover, inflammation, and more specifically proinflammatory cytokines and other molecules with a relevant role within the inflammatory process, may be critical factors in the development of microvascular diabetic complications, including nephropathy. This new pathogenic perspective may lead to important new therapeutic considerations and new therapeutic goals for the treatment of diabetic nephropathy.

KEYWORDS: Diabetes, Diabetic nephropathy, Inflammation, Proinflammatory cytokines

\section{INTRODUCTION}

Diabetes mellitus, specially type 2 diabetes, is a public health problem that has reached the range of epidemic due to the rapidly increasing rates of the disease throughout the world. More important, the prevalence of type 2 diabetes will continue to rise in the next 20 years, with the great concern that this disease is rising rapidly in children and adolescents worldwide[1].

From this perspective, it is easily understandable that target organ complications secondary to diabetes will be one of the most important medical concerns in the next decades. A clear example is diabetic nephropathy (DN), "a medical catastrophe of worldwide dimensions," which has become the single-most frequent cause of end-stage renal disease[2].

\section{DIABETES MELLITUS: FROM A METABOLIC DISORDER TO AN INFLAMMATORY CONDITION}

Perspectives on type 2 diabetes have changed substantially in the last decade with the notion that chronic, low-grade inflammation and activation of the innate immune system are closely involved in the 
pathogenesis of this disease. This hypothesis was first proposed in 1997 and 1998, and suggested that long-term innate immune system activation, resulting in chronic inflammation, elicited disease instead of repair leading to the development of type 2 diabetes[3]. Several cross-sectional studies in the general population, as well as in nondiabetic subjects, in individuals with impaired glucose tolerance (IGT)/impaired fasting glucose (IFG) and in newly diagnosed or established type 2 diabetic patients have shown that acute-phase reactants and proinflammatory cytokines, such as C-reactive protein (CRP), sialic acid, tumor necrosis factor- $\alpha$ (TNF- $\alpha$ ), and interleukin-6 (IL-6), are positively correlated with measures of insulin resistance[4,5,6,7,8,9]. Furthermore, diabetic patients exhibit elevated levels of these parameters compared with nondiabetic control subjects[7,8,10,11,12].

The Atherosclerosis Risk in Communities Study was the first work to show that inflammatory markers predict the development of type 2 diabetes[13,14]. Subsequent studies, including the U.S. Women's Health Study[15], the U.S. Insulin Resistance and Atherosclerosis Study[16], or the European Prospective Investigation into Cancer and Nutrition (EPIC)-Postdam Study[17], have confirmed that circulating inflammatory markers, acute-phase reactants, and proinflammatory cytokines are strongly associated with the risk of developing type 2 diabetes. In addition, the findings that anti-inflammatory agents decrease the acute-phase response and may reduce the risk of developing type 2 diabetes are of great interest. Yuan et al.[18] reported that insulin resistance in genetically obese $f a / f a$ rats and $o b / o b$ mice is reversed by salicylates via an IкB kinase $\beta$-dependent mechanism. In the West of Scotland Coronary Prevention Study[19], assignment to pravastatin therapy resulted in a 30\% reduction in the risk of developing type 2 diabetes, which may be related to the drug's anti-inflammatory properties (inhibiting release of cytokines by up-regulating peroxisome proliferator-activated receptor (PPAR)- $\alpha$ and $-\gamma$ and inhibiting the NF-kb pathway)[20,21]. Finally, several studies with the recently introduced thiazolidinediones have reported a significant improvement in insulin sensitivity[22] as well as a decrease in the risk of progression to diabetes in subjects with a known high risk for developing this disease[23]. In addition to their actions as PPAR- $\gamma$ agonists, glitazones have anti-inflammatory effects with inhibition of cytokine production, macrophage activation, and reduction of the levels of inflammatory markers such as $\mathrm{CRP}[24,25,26]$.

The mechanisms by which chronic inflammation can evoke type 2 diabetes are not completely clear, but probably a conjunction of aspects has to be taken into account, including genetic, metabolic, and environmental factors. It has been postulated that in type 2 diabetes and IGT, prolonged lifestyle or environmental stimulants cause maladaptation to the normal physiological responses, causing disease instead of repair[6]. It is known that adipose tissue is able to synthesize and release the main proinflammatory cytokines - TNF- $\alpha$, interleukin-1 (IL-1), and IL-6 - and that inflammatory markers are associated with body fat mass. Proinflammatory cytokines and acute-phase reactants are involved in multiple metabolic pathways relevant to insulin resistance, including insulin regulation, reactive oxygen species, lipoprotein lipase action, and adipocyte function[27]. There are clear examples that show the relevant role of different molecules such as PPAR- $\gamma$, free fatty acids (FFA), GLUT4 (the insulinresponsive glucose transporter), and the suppressors of the cytokine signaling (SOCS) in proinflammatory cytokine-induced insulin resistance. Proinflammatory cytokines are associated with a significant downregulation of PPAR- $\gamma$ expression[28]. FFA are known to produce insulin resistance dose dependently in skeletal muscle and liver[29]. In muscle, through mechanisms that involve intracellular accumulation of long-chain acyl-CoA and diacylglycerol, activation of protein kinase $\mathrm{C}$ (PKC), and decreased tyrosine phosphorylation of insulin receptor substrate (IRS)-1/2[30,31], FFA inhibit insulin-stimulated glucose uptake[32,33]. Concerning hepatic insulin resistance, FFA are associated with increased hepatic diacylglycerol content, increased activities of $\mathrm{PKC}-\delta$ and inhibitor of $\kappa \mathrm{B}$-kinase (IKK), enhanced activation of nuclear factor- $\kappa \mathrm{B}$, and increased expression of the inflammatory cytokines TNF- $\alpha$ and IL$1 \beta[34]$. Recent experimental studies have demonstrated that TNF- $\alpha$ is also able to impair insulin stimulation of glucose uptake and GLUT4 translocation to the plasma membrane. This cytokine, through activation of IKK in a p38 mitogen-activated protein kinase-dependent manner, produces serine phosphorylation of insulin receptor (IR) and IRS-1, impairing its tyrosine phosphorylation by insulin and 
the corresponding activation of phosphatidylinositol 3-kinase and Akt[35]. Furthermore, in vitro studies have shown that even very low TNF- $\alpha$ concentrations resulted in repression of GLUT4 gene transcription and decreased GLUT4 mRNA stability[36,37]. Finally, proinflammatory cytokine-induced insulin resistance has been related to SOCS proteins. Eight SOCS family members have been identified as inhibitors of cytokine signaling, suggesting that they play a role in the negative feedback control of cytokine pathway[38,39,40]. Diverse proinflammatory cytokines, including TNF- $\alpha$, IL-1, and IL-6, are able to induce one or more SOCS proteins in different tissues[38,39]. It has been demonstrated that SOCS-1 and SOCS-6 inhibit insulin-dependent IR-directed phosphorylation of IRS-1[40]. On the other hand, specific polymorphisms in the TNF- $\alpha$ and IL-6 genes are variously associated with insulin sensitivity or resistance[41,42]. Therefore, activated innate immunity and inflammation are relevant factors in the pathogenesis of diabetes, with convincing data that type 2 diabetes includes an inflammatory component[6,27].

\section{PROINFLAMMATORY CYTOKINES AND DIABETIC NEPHROPATHY}

Our knowledge on DN concerning different aspects, such as risk factors, clinical course, factors that influence the severity as well as the progression of renal injury, and the possibilities of effective therapeutic approaches, have significantly improved in the last years. Both metabolic and hemodynamic factors are critical for the risk of developing DN. However, in spite of this improvement in our knowledge on $\mathrm{DN}$, from a pathophysiological point of view, the intimate mechanisms leading from chronic hyperglycemia to the development of renal injury are complex and not yet fully known.

A number of experimental and clinical studies have demonstrated the significant role of various inflammatory molecules in the setting of DN, including acute phase reactants, inflammatory cytokines, adhesion molecules, and chemokines. Dalla Vestra et al.[43] showed that patients with type 2 diabetes and overt nephropathy exhibit elevated levels of diverse acute-phase markers of inflammation and proinflammatory cytokines, including CRP, serum amyloid A (SAA), and IL-6, which were higher in subjects with increased glomerular basement membrane (GBM) width, a crucial lesion of diabetic glomerulopathy. Furthermore, they observed a significant association of GBM thickening with fibrinogen and IL-6. Chow et al.[44] showed that db/db mice, a model of type 2 diabetes and DN, exhibited an increased expression of intracellular adhesion molecule (ICAM-1), which promotes inflammation in glomeruli and tubules by increasing leukocyte infiltration and adherence, along with a marked increase in macrophage infiltration. In a model of diabetes and hypertension, Kelly et al.[45] demonstrated that urinary albumin excretion was reduced and renal function was preserved in rats treated with ruboxistaurin, an inhibitor of protein-kinase $\mathrm{C}-\beta$, in spite of hyperglycemia and elevated blood pressure. PKC has various isoforms that are activated in diabetes and signal a number of cellular responses, including activation and expression of inflammatory mediators, such as proinflammatory cytokines[46]. In another study, Banba et al.[47] showed that diabetic patients had elevated urinary levels of monocyte chemoattractant protein-1 (MCP-1), with a significant association between urinary levels of albumina and $\mathrm{MCP}-1$. These findings suggest that MCP-1 contributes to the initiation and progression of DN.

Hasegawa et al.[48] suggested for the first time that proinflammatory cytokines could participate in the development of DN. In that study, macrophages incubated with GBM from diabetic rats produced significantly greater levels of IL-1 and TNF- $\alpha$ than macrophages incubated with membranes of normal nondiabetic rats. A number of experimental studies have demonstrated that diverse intrinsic renal cells, such as endothelial, mesangial, glomerular, and tubular epithelial cells, are able to synthesize proinflamamatory cytokines, molecules that have been associated with significant renal effects. IL-1 increases vascular endothelial permeability and has been involved in the proliferation of mesangial cells and matrix synthesis, as well as in the development of intraglomerular microcirculatory abnormalities related to prostaglandin production by mesangial cells[49,50,51]. Regarding IL-6, this cytokine affects extracellular matrix dynamics at both mesangial and podocyte levels, stimulates proliferation of 
mesangial cells, increases fibronectin expression, and enhances endothelial permeability[43,52]. Finally, most attention has been focused on the implications of TNF- $\alpha$ in the setting of DN in the last years.

\section{Tumor Necrosis Factor- $\alpha$ and Diabetic Nephropathy}

The synthesis of human TNF- $\alpha$ starts with the elaboration of a prohormone, a 26-kD membrane associated form, which either serves as a precursor for the soluble molecule or binds without processing to the TNF- $\alpha$ receptors via cell-to-cell contacts[53]. This cytokine is synthesized primarily by monocytes/macrophages, although diverse studies have demonstrated that intrinsic renal cells, including glomerular, mesangial, endothelial, and tubular cells, are able to produce inflammatory cytokines that play a role in controlling growth, biosynthetic activities, and functions of cells[54,55,56,57]. Recent experimental investigations by our group have demonstrated that renal mRNA expression for TNF- $\alpha$ is significantly increased by approximately 2.5 -fold in diabetic rats compared to normal rats[58].

A variety of bioactivities suggests that this cytokine may promote the development of diabetic microvascular complications. TNF- $\alpha$ has been implicated in the hemodynamic disbalance between vasodilatory and vasoconstrictive mediators, which may result in alterations of glomerular blood flow and glomerular filtration rate[59]. It has also been reported that this cytokine is cytotoxic to glomerular, mesangial, and epithelial cells, and may induce direct renal damage[60,61]. McCarthy et al.[62] demonstrated that TNF- $\alpha$ was able to promote the local generation of reactive oxygen species with a subsequent alteration of the barrier function of the glomerular capillary wall, resulting in enhanced albumin permeability, independently of hemodynamic factors or effects of recruited inflammatory cells. Experimental studies in animal models of DN have demonstrated that urinary albumin excretion significantly correlates with renal cortical mRNA levels and urinary TNF- $\alpha$ excretion. Moreover, increased urinary TNF- $\alpha$ excretion, as well as increased TNF- $\alpha$ levels in renal interstitial fluid, preceded the significant increase in albuminuria[58,63]. Exposure of tubular epithelial cells to TNF- $\alpha$ significantly increased the synthesis and secretion of lymphocyte and neutrophil chemoattractant factors[64], as well as the cell surface expression of ICAM-1[65,66], which has been implicated in the development of renal injury in diabetes[66]. Finally, TNF- $\alpha$ has stimulatory effects on sodium uptake by proximal tubule cells[67], contributing to sodium retention and renal hypertrophy, typical alterations during the early stage of DN[68].

In addition to the observations from experimental investigations, clinical studies have found a direct and significant association between serum TNF- $\alpha$ and urinary protein excretion in diabetic patients with normal renal function and microalbuminuria, as well as in subjects with overt nephropathy and renal insufficiency[10,69]. On the other hand, urinary TNF- $\alpha$ levels are also elevated in diabetic patients with increased urinary albumin excretion, and furthermore, there is a significant rise of urinary TNF- $\alpha$ excretion as DN progressed. Moreover, multivariate analysis shows a significant and independent relationship between urinary TNF- $\alpha$ and urinary albumin excretion. Interestingly, in these studies, a significant correlation between serum and urinary concentrations of TNF- $\alpha$ was not found, suggesting an intrarenal production of this cytokine[10].

\section{ANTI-INFLAMMATORY THERAPIES FOR DIABETIC NEPHROPATHY}

Nowadays, available therapies for prevention or slow progression of $\mathrm{DN}$ are based on strict metabolic control and treatment of hypertension with inhibitors of the rennin-angiotensin system[70,71,72,73,74,75]. However, these strategies provide imperfect protection, being necessary innovative approaches with novel treatments[76]. The vision of DN as an inflammatory disease triggered by altered metabolic factors opens new and important therapeutic perspectives. 
Different studies in experimental models of DN have shown that the administration of substances with anti-inflammatory properties, including cyclooxigenase-2 inhibitors, mycophenolate mophetil, or mizoribine, were able to reduce the expression of mediators of renal injury as well as prevent the development of glomerular and tubulointerstitial damage[77,78,79]. More importantly, diverse recent clinical studies have demonstrated that some of these strategies based on the modulation of inflammatory molecules may have important translational implications.

The final product of the rennin-angiotensin-aldosterone system, aldosterone, has been implicated as an important factor mediating renal disease[80,81]. Rossing et al.[82] have shown in a short-term, randomized, double-masked, placebo-controlled, cross-over trial that addition of a low dose of the aldosterone blocker, spironolactone, to the recommended maxium doses of angiotensin-converting enzyme inhibitors and/or angiotensin II type 1 receptor blockers may offer beneficial renoprotection as reflected by reductions in blood pressure and albuminuria in type 2 diabetic patients with nephropathy. Interestingly, an experimental work in type 2 diabetic rats showed that spironolactone treatment significantly inhibited urinary excretion of (MCP-1) as well as the renal expression of this factor[83]. These experimental findings have been recently confirmed in patients with type 2 diabetes complicated by $\mathrm{DN}[84]$.

Evidence over the last decade has implicated PKC as an important mediator of diabetes-induced vascular dysfunction[85]. This enzyme is composed of different isoforms, various of which are activated in diabetes, especially PKC- $\beta$. This molecule signals a number of cellular responses, including oxidative stress, expression and/or activation of inflammatory mediators, cellular proliferation, and tissue fibrosis[86]. A clinical trial designed to evaluate the effect of ruboxistaurin, a specific PKC- $\beta$ inhibitor, has been recently published. In this pilot study, Tuttle et al.[87] showed that ruboxistaurin had favorable effects on urinary albumin excretion and renal function in type 2 diabetic patients with nephropathy, with the albuminuria-lowering effect occurring early and sustained long term.

Pentoxifylline (PTF) is a methylxanthine-derivate phosphodiesterase inhibitor widely used in the treatment of peripheral circulatory disorders based on its beneficial hemorheological activity. In addition, PTF possesses significant inmmunological and anti-inflammatory properties. It has been demonstrated that PTF inhibits the accumulation of TNF- $\alpha$ mRNA and the transcription of the TNF- $\alpha$ gene, suppressing the synthesis of this cytokine[88,89]. In different models of renal disease, including lupus nephritis[90], crescentic glomerulonephritis[91], mesangial proliferative glomerulonephritis[92], and remnant kidney model[93] — in all of them with inflammatory mediators such as TNF- $\alpha$ or ICAM-1 playing a significant role - PTF has shown beneficial effects preventing or attenuating renal injury. Regarding DN, recent studies by DiPetrillo and Gesak[94], as well as by our group (unpublished data), have reported that PTF administration was able to prevent the increased renal TNF- $\alpha$ expression, synthesis, and excretion during experimental diabetes. In addition, PTF therapy ameliorated renal sodium retention and renal hypertrophy, the initial pathological changes associated with DN.

In addition to these experimental observations, clinical results support the efficacy of PTF as a therapeutic agent for DN. It has been shown that PTF reduces urinary protein excretion in diabetic subjects, both with normal renal function[95,96] and renal insufficiency[69]. Furthermore, addition of PTF to blockers of the rennin-angiotensin system, both angiotensin-converting enzyme inhibitors[97] or angiotensin II type 1 receptor blockers[98], has been associated with a significant reduction of urinary albumin excretion. Importantly, diabetic patients with residual albuminuria after long-term treatment with ARB may obtain a beneficial additive antialbuminuric effect of PTF, which is significant and directly related to a reduction of urinary TNF- $\alpha$ excretion[98]. Finally, in a very recent study in patients with proteinuric primary glomerular diseases, PTF significantly reduced urinary protein excretion, along with an increase of serum albumin. This beneficial effect occurred in close association with a reduction of urinary MCP-1 excretion[99]. 


\section{CONCLUSIONS}

Based on estimations by the World Health Organization, by the year 2025, over 300 million people worldwide will have diabetes[100]. About $25-40 \%$ of patients with type 1 diabetes and $30-40 \%$ of type 2 diabetic subjects will develop DN, which has now become the single-most common cause of end-stage renal disease in the Western world, with over half of all patients on renal replacement programs now having diabetes[101]. The pathogenic vision of diabetes mellitus has substantially changed in the last years. The knowledge we have today on the pathogenesis of DN indicates that diabetes-associated alteration in diverse metabolic and hemodynamic pathways activate adhesion molecules, chemokines, growth factors, and cytokines. Therefore, DN can be viewed as an inflammatory disease triggered by disordered metabolism[102]. Current treatment of the nephropathy complication of diabetes is suboptimal in halting the progression of this complex disease. The recent insights on the role of inflammatory pathways in the development of renal damage in diabetes provide strong rationale for anti-inflammatory approaches to be used in the therapy of DN. Modulation of these inflammatory processes is emerging as an innovative strategy that can be fully translated into clinical treatments in a near future.

\section{ACKNOWLEDGMENTS}

The studies by the authors have been supported by Fundación Canaria de Investigación y Salud (FUNCIS), Sociedad Española de Nefrología (SEN), and Asociación Científica para la Investigación Nefrológica (ACINEF).

\section{REFERENCES}

1. Vivian, E.M. (2006) Type 2 diabetes in children and adolescents - the next epidemic? Curr. Med. Res. Opin. 22, 297306.

2. Ritz, E., Rychlik, I., Locatelli, F., and Halimi, S. (1999) End-stage renal failure in type 2 diabetes: a medical catastrophe of worldwide dimensions. Am. J. Kidney Dis. 34, 795-808.

3. Pickup, J. and Crook, M. (1998) Is type II diabetes mellitus a disease of the innate immune system? Diabetologia 41, 1241-1248.

4. Festa, A., D’Agostino, R., Howard, G., Mykkänen, L., Tracy, R.P., and Haffner, S.M. (2000) Chronic subclinical inflammation as part of the insulin resistance syndrome: the Insulin Resistance Atherosclerosis Study (IRAS). Circulation 101, 42-47.

5. Ford, E.S. (1999) Body mass index, diabetes, and C-reactive protein among US adults. Diabetes 22, $1971-1977$.

6. Müller, S., Martin, S., Koenig, W., Hanifi-Moghaddam, P., Rathmann, W., Haastert, B., Giani, G., Illig, T., Thorand, B., and Kolb, H. (2002) Impaired glucose tolerance is associated with increased serum concentrations of interleukin 6 and co-regulated acute-phase proteins but not TNF- $\alpha$ or its receptors. Diabetologia 45, 805-812.

7. Temelkova-Kurktschiev, T., Henkel, E., Koelher, C., Karrei, K., and Hanefield, M. (2002) Subclinical inflammation in newly detected type II diabetes and impaired glucose tolerance. Diabetologia 45, 151

8. Rodríguez-Morán, M. and Guerrero-Romero, F. (1999) Increased levels of C-reactive protein in noncontrolled type II diabetic subjects. J. Diabetes Complications 13, 211-215.

9. Leinonen, E., Hurt-Camejo, E., Wiklund, O., Hultén, L.M., Hiukka, A., and Taskinen, R.M. (2001) Insulin resistance and adiposity correlate with acute-phase reaction and soluble cell adhesion molecules in type 2 diabetes. Atherosclerosis 166, 387-394.

10. Navarro, J.F., Mora, C., Macía, M., and García, J. (2003) Inflammatory parameters are independently associated with urinary albumin excretion in type 2 diabetes mellitus. Am. J. Kidney Dis. 42, 53-61.

11. Katsuki, A., Sumida, Y., Murashima, S., Murata, K., Takarada, Y., Ito, K., Fujii, M., Tsuchihashi, K., Goto, H., and Nakatani, K. (1998) Serum levels of tumor necrosis factor-alpha are increased in obese patients with noninsulindependent diabetes mellitus. J. Clin. Endocrinol. Metab. 83, 859-862.

12. Pickup, J.C., Chusney, G.C., Thomas, S.M., and Burt, D. (2000) Plasma interleukin-6, tumor necrosis factor alpha and blood cytokine production in type 2 diabetes. Life Sci. 67, 291-300.

13. Schmidt, M.I., Duncan, B.B., Sharrett, A.R., Lindberg, G., Savage, P.J., Offenbacher, S., Azambuja, M.I., Tracey, R.P., and Heiss, G. (1999) Markers of inflammation and prediction of diabetes mellitus in adults (Atherosclerosis Risk in Communities study): a cohort study. Lancet 353, 1649-1652. 
14. Duncan, B.B., Schmidt, M.I., Offenbacher, S., Wu, K.K., Savage, P.J., and Heiss, G. (1999) Factor VIII and other hemostasis variables are related to incident diabetes in adults: the Atherosclerosis Risk in Communities (ARIC) study. Diabetes Care 22, 767-772.

15. Pradhan, A.D., Manson, J.E., Rifai, N., Buring, J.E., and Ridker, P.M. (2001) C-reactive protein, interleukin 6, and risk of developing type 2 diabetes mellitus. JAMA 286, 327-334.

16. Festa, A., D’Agostino, R., Tracey, R.P., and Haffner, S.M. (2002) Elevated levels of acute-phase proteins and plasminogen activator inhibitor-1 predict the development of type 2 diabetes: the Insulin Resistance Atherosclerosis Study. Diabetes 51, 1131-1137.

17. Spranger, J., Kroke, A., Möhlig, M., Hoffman, K., Bergman, M.M., Ristow, M., Boeing, H., and Pfeiffer, A.F.H. (2003) Inflammatory cytokines and the risk to develop type 2 diabetes: results of the prospective population-based European Prospective Investigation into Cancer and Nutrition (EPIC) Postsdam study. Diabetes 52, 812-817.

18. Yuan, M., Konstantopoulos, N., Lee, J., Hansen, L., Li, Z.W., Karim, M., and Shoelson, S.E. (2001) Reversal of obesity- and diet-induced insulin resistance with salicylates or targeted disruption of Ikkbeta. Science 293, 16731677.

19. Freeman, D.J., Norrie, J., Naveed, S., Neely, D.G., Cobbe, S.M., Ford, I., Isles, C., Lorimer, A.R., Macfarlane, P.W., McKillop, J.H., Packard, C.J., Shepherd, J., and Gaw, A. (2001) Pravastatin and the development of diabetes mellitus: evidence for a protective treatment effect in the West of Scotland Coronary Prevention Study. Circulation 103, 357362.

20. Weitz-Schmidt, G. (2002) Statins as anti-inflammatory agents. Trends Pharmacol. Sci. 23, 482-486.

21. McFarlane, S.I., Muniyappa, R., Francisco, R., and Stowers, J.R. (2002) Pleiotropic effects of statins: lipid reduction and beyond. J. Clin. Endocrinol. Metab. 87, 1451-1458.

22. Levin, K., Hother-Nielsen, O., Henriksen, J.E., and Beck-Nielsen, H. (2004) Effects of troglitazone in young firstdegree relatives of patients with type 2 diabetes. Diabetes Care 2, 148-154.

23. Anderson, D.C., Jr. (2005) Pharmacologic prevention or delay of type 2 diabetes mellitus. Ann. Pharmacother. 39, 102-109.

24. Ricote, M., Li, A.C., Wilson, T.M., Kelly, C.J., and Glass, C.K. (1998) The peroxisome proliferator-activated receptor- $\gamma$ is a negative regulator of macrophage activation. Nature 391, 79-82.

25. Jiang, C., Ting, A.T., and Seed, B. (1998) PPAR- $\gamma$ agonists inhibit production of monocyte inflammatory cytokines. Nature 391, 82-85.

26. Haffner, S.M., Greenberg, A.S., Weston, W.M., Chen, H., Williams, K., and Freed, M.I. (2002) Effect of rosiglitazone treatment on non-traditional markers of cardiovascular disease in patients with type 2 diabetes mellitus. Circulation 106, 679-684.

27. Crook, M. (2004) Type 2 diabetes mellitus: a disease of the innate immune system? An update. Diabet. Med. 21, 203207.

28. Tanaka, T., Itoh, H., Doi, K., Fukunaga, K., Shintani, M., Yamashita, J., Chun, T.H., Inoue, M., Masatsugu, K., Sawada, N., Saito, T., Nishimura, H., Yoshimasa, Y., and Nakao, K. (1999) Downregulation of peroxisome proliferators-activated receptor $\gamma$ expression by inflammatory cytokines and its reversal by thiazolidinediones. Diabetologia 42, 702-710.

29. Boden, G. (2004) Free fatty acids as target for therapy. Curr. Opin. Endocrinol. Diab. 11, 258-263.

30. Itani, S., Ruderman, N., Schmieder, S., and Boden, G. (2002) Lipid-induced insulin resistance in human muscle is associated with changes in diacylglycerol, protein kinase $\mathrm{C}$, and IкB- $\alpha$. Diabetes 51, 2005-2011.

31. Samuel, V., Liu, Z., Qu, X., Elder, B., Bilz, S., Befroy, D., Romanelli, A., and Shulman, G. (2004) Mechanism of hepatic insulin resistance in non-alcoholic fatty liver disease. J. Biol. Chem. 279, 32345-32353.

32. Boden, G. and Chen, X. (1995) Effects of fat on glucose uptake and utilization in patients with non-insulin-dependent diabetes. J. Clin. Invest. 96, 1261-1268.

33. Dresner, A., Laurent, D., Marcucci, M., Griffin, M.E., Dufour, S., Cline, G., Slezak, L., Andersen, D., Hundal, R., Rothman, D., Petersen, K., and Shuman, G. (1999) Effects of fatty acids on glucose transport and IRS-1 associated phosphatidylinositol 3-kinase activity. J. Clin. Invest. 103, 253-259.

34. Boden, G., She, P., Mozzoli, M., Cheung, P., Gumireddy, K., Reddy, P., Xiang, X., Luo, Z., and Ruderman, N. (2005) Free fatty acids produce insulin resistance and activate the proinflammatory nuclear factor- $\kappa \mathrm{B}$ pathway in rat liver. Diabetes 54, 3458-3465.

35. De Alvaro, C., Teruel, T., Hernández, R., and Lorenzo, M. (2004) Tumor necrosis factor $\alpha$ produces insulin resistance in skeletal muscle by activation of inhibitor $\kappa \mathrm{B}$ kinase in a p38 MAPK-dependent manner. J. Biol. Chem. 279, 17070-17078.

36. Stephens, J. and Pekala, P. (1992) Transcriptional repression of C/EBP and GLUT4 genes in the 3T3-L1 adipocytes by tumor necrosis factor- $\alpha$ : regulation is coordinate and independent of protein synthesis. J. Biol. Chem. 267, 1358013584.

37. Stephens, J., Lee, J., and Pilch, P. (1997) Tumor necrosis factor- $\alpha$ induced insulin resistance in 3T3-L1 adipocytes is accompanied by a loss of insulin receptor substrate-1 and GLUT4 expression without a loss of insulin receptor mediated signal transduction. J. Biol. Chem. 272, 971-976.

38. Starr, R., Willson, T.A., Viney, E., Murray, L., Rayner, J., Jenkins, B., Gonda, T., Alexander, W., Metcalf, D., Nicola, N., and Hilton, D. (1997) A family of cytokine-inducible inhibitors of signalling. Nature 387, 917-921. 
39. Krebs, D. and Hilton, D. (2000) SOCS: physiological suppressors of cytokine signalling. J. Cell Sci. 113, $2813-2819$.

40. Mooney, R., Senn, J., Cameron, S., Inamdar, N., Boivin, L., Shag, Y., and Furlanetto, R. (2001) Suppressors of cytokine signialing-1 and -6 associate with and inhibit the insulin receptor. J. Biol. Chem. 276, 25889-25893.

41. Day, C.P., Grove, J., Daly, A.K., Stewart, M.W., Avery, P.J., and Walker, M. (1998) Tumor necrosis factor alpha gene promoter polymorphism and decreased insulin resistance. Diabetologia 41, 430-434.

42. $\quad$ Fernández-Real, J., Vendrell, J., Ricart, W., Broach, M., Gutiérrez, C., Casamitjana, R., Oriola, J., and Richard, C. (2000) Interleukin-6 gene polymorphism and insulin sensitivity. Diabetes 49, 517-520.

43. Dalla Vestra, M., Mussap, M., Gallina, P., Bruseghin, M., Cernigoi, A.M., Saller, A., Plebani, M., and Fioretto, P. (2005) Acute-phase markers of inflammation and glomerular structure in patients with type 2 diabetes. J. Am. Soc. Nephrol. 16, S78-S82.

44. Chow, F.Y., Nikolic-Paterson, D.J., Ozols, E., Atkins, R.C., and Tesch, G.H. (2005) Intracellular adhesion molecule-1 deficiency is protective against nephropathy in type 2 diabetic db/db mice. J. Am. Soc. Nephrol. 16, 1711-1722.

45. Kelly, D.J., Chanty, A., Gow, R.M., Zhang, Y., and Gilbert, R.E. (2005) Protein kinase C beta inhibition attenuates osteopontin expression, macrophage recruitment, and tubulointerstitial injury in advanced experimental nephropathy. J. Am. Soc. Nephrol. 16, 1654-1660.

46. Shanmugam, N., Reddy, M.A., Guha, M., and Natarajan, R. (2003) High glucose-induced expression of proinflammatory cytokine and chemokine genes in monocytic cells. Diabetes 52, 1256-1264.

47. Banba, N., Nakamura, T., et al. (2000) Possible relationship of monocyte chemoattractant protein-1 with diabetic nephropathy. Kidney Int. 58, 684-690. Possible role of tumor necrosis factor and interleukin-1 in the development of diabetic nephropathy. Kidney Int. 40, 1007-1012.

Royall, J.A., Berkow, R.L., Beckman, J.S., Cunningham, M.K., Matalon, S., and Freeman, B.A. (1989) Tumor necrosis factor and interleukin 1 increase vascular endothelial permeability. Am. J. Physiol. 257, L339-L410.

50. Melcion, C., Lachman, L., Killen, D., Morel-Maroger, L., and Striker, G.E. (1982) Mesangial cells, effect of monocyte products on proliferation, and matrix synthesis. Transplant. Proc. 14, 559-564.

51. Pfeilschfer, J., Pignat, W., Vosbeck, K., and Märki, F. (1989) Interleukin 1 and tumor necrosis factor synergistically stimulate prostaglandin synthesis and phospholipase A2 release from rat renal mesangial cells. Biochem. Biophys. Res. Commun. 159, 385-394.

52. Hirano, T., Akira, S., Taga, T., and Kishimoto, T. (1990) Biological and clinical aspect of interleukin 6. Immunol. Today 11, 443-449.

53. Baud, L. and Ardaillou, R. (1995) Tumor necrosis factor in renal injury. Miner. Electrolyte Metab. 21, 336-341.

54. Noronha, I.L., Niemir, Z., Stein, H., and Waldherr, R. (1995) Cytokines and growth factors in renal disease. Nephrol. Dial. Transplant. 10, 775-786.

55. Hasegawa, G., Nakano, K., and Kondo, M. (1995) Role of TNF and IL-1 in the development of diabetic nephropathy. Nefrologia 15, 1-4.

56. Nakamura, T., Fukui, M., Ebihara, I., Osada, S., Nagaoka, I., Tomino, Y., and Koide, H. (1993) mRNA expression of growth factors in glomeruli of diabetic rats. Diabetes 42, 450-456.

57. Sugimoto, H., Shikata, K., Wada, J., Horiuchi, S., and Makino, H. (1999) Advanced glycation end products-cytokinenitric oxide sequence pathway in the development of diabetic nephropathy: aminoguanidine ameliorates the overexpression of tumour necrosis factor- $\alpha$ and inducible nitric oxide synthase in diabetic rat glomeruli. Diabetologia 42, 878-886.

58. Navarro, J., Milena, F., Mora, C., León, C., Claveríe, F., Flores, C., and García, J. (2005) Tumor necrosis factor- $\alpha$ gene expression in diabetic nephropathy: relationship with urinary albumin excretion and effect of angiotensinconverting enzyme inhibition. Kidney Int. 68(Suppl 99), S98-S102.

59. Baud, L., Pérez, J., Friedlander, G., and Ardaillou, R. (1988) Tumor necrosis factor stimulates prostaglandin production and cyclic AMP levels in rat cultured mesangial cells. FEBS Lett. 239, 50-54.

60. Ortiz, A., González-Cuadrado, S., Bustos, C., Alonso, J., Gómez-Guerrero, C., López-Armada, M.J., González, E., Plaza, J.J., and Egido, J. (1995) Tumor necrosis factor as a mediator of glomerular damage. J. Nephrol. 8, 27-34.

61. Bertani, T., Abbate, M., Zoja, C., Corna, D., Perico, N., Ghezzi, P., and Remuzzi, G. (1989) Tumor necrosis factor induces glomerular damage in rabbit. Am. J. Pathol. 134, 419-430.

62. MaCarthy, E., Sharma, R., Sharma, M., Li, J.Z.; Ge, X.L., Dileepan, K.N., and Savin, V.J. (1998) TNF- $\alpha$ increases albumin permeability of isolated rat glomeruli through the generation of superoxide. J. Am. Soc. Nephrol. 9, 433-438.

63. Kalantarinia, K., Awas, A.S., and Siragy, H.M. (2003) Urinary and renal interstitial concentrations of TNF- $\alpha$ increase prior to the rise in albuminuria in diabetic rats. Kidney Int. 64, 1208-1213.

64. Schmouder, R.L., Strieter, R.M., Wiggins, R.C., Chensue, S.W., and Kunkel, S.L. (1992) In vitro and in vivo interleukin-8 production in human renal cortical epithelia. Kidney Int. 41, 191-198.

65. Ishikura, H., Takahashi, C., Kanagawa, K., Hirata, H., Imai, K., and Yoshiki, T. (1991) Cytokine regulation of ICAM1 expression on human renal tubular epithelial cells in vitro. Transplantation 51, 1272-1275.

66. Chow, F.Y., Nikolic-Paterson, D.J., Ozols, E., Atkins, R.C., and Tesch, G.H. (2005) Intercellular adhesion molecule-1 deficiency is protective against nephropathy in type 2 diabetic db/db mice. J. Am. Soc. Nephrol. 16, 1711-1722.

67. Schreiner, G.F. and Kohan, D.E. (1990) Regulation of renal transport processes and hemodynamics by macrophages 
and lymphocytes. Am. J. Physiol. 258, F761-F767.

68. Dipetrillo, K., Coutermarsh, B., and Gesek, F.A. (2003) Urinary tumor necrosis factor contributes to sodium retention and renal hypertrophy during diabetes. Am. J. Physiol. Renal Physiol. 284, F113-F121.

69. Navarro, J.F., Mora, C., Rivero, A., Gallego, E., Chahin, J., Macia, M., Mendez, M.L., and Garcia, J. (1999) Urinary protein excretion and serum tumor necrosis factor in diabetic patients with advanced renal failure: effects of pentoxifylline administration. Am. J. Kidney Dis. 33, 458-463.

70. The Diabetes Control and Complications Trial Research Group (1993) The effect of intensive treatment of diabetes on the progression of long-term complications in insulin-dependent diabetes mellitus. N. Engl. J. Med. 329, 977-986.

71. United Kingdom Prospective Diabetes Study (UKPDS) Group (1998) Intensive blood glucose control with sulfonylureas or insulin compared with conventional treatment and risk of complications in patients with type 2 diabetes (UKPDS 33). Lancet 352, 837-853.

72. Lewis, E.J., Hunsicker, L.G., Bain, R.P., and Rohde, R.D. (1993) The effect of angiotensin-converting-enzyme inhibition on diabetic nephropathy. The Collaborative Study Group. N. Engl. J. Med. 329, 1456-1462.

73. Brenner, B.M., Cooper, M.E., de Zeeuw, D., Keane, W.F., Mitch, W.E., Parving, H.H., Remuzzi, G., Snapinn, S.M., Zhang, Z., and Shahinfar, S. (2001) Effects of losartan on renal and cardiovascular outcomes in patients with type 2 diabetes and nephropathy. N. Engl. J. Med. 345, 861-869.

74. Lewis, E.J., Hunsicker, L.G., Clarke, W.R., Berl, T., Pohl, M.A., Lewis, J.B., Ritz, E., Atkins, R.C., Rohde, R., and Raz, I. (2001) Renoprotective effect of the angiotensin-receptor antagonist irbesartan in patients with nephropathy due to type 2 diabetes. N. Engl. J. Med. 345, 851-860.

75. Ruggenenti, P., Fassi, A., Ilieva, A.P., Bruno, S., Iliev, I.P., Brusegan, V., Rubis, N., Gherardi, G., Arnoldi, F., Ganeva, M., Ene-Iordache, B., Gaspari, F., Perna, A., Bossi, A., Trevisan, R., Dodesini, A.R., Remuzzi, G.; Bergamo Nephrologic Diabetes Complications Trial (BENEDICT) Investigators (2004) Preventing microalbuminuria in type 2 diabetes. N. Engl. J. Med. 351, 1941-1951.

76. Hostetter, T.H. (2001) Prevention of end-stage renal disease due to type 2 diabetes. N. Engl. J. Med. 345, 910-912.

77. Cheng, H.F., Wang, C.J., Moeckel, G.W., Zhang, M.Z., McKanna, J.A., and Harris, R.C. (2002) Cyclooxygenase-2 inhibitor blocks expression of mediators of renal injury in a model of diabetes and hypertension. Kidney Int. 62, 929939.

78. Utimura, R., Fujihara, C.K., Mattar, A.L., Malheiros, D.M., Noronha, I.L., and Zatz, R. (2003) Mycophenolate mofetil prevents the development of glomerular injury in experimental diabetes. Kidney Int. 63, 209-216.

79. Kikuchi, Y., Imakiire, T., Yamada, M., Saigusa, T., Hyodo, T., Hyodo, N., Suzuki, S., and Miura, S. (2005) Mizoribine reduces renal injury and macrophage infiltration in non-insulin-dependent diabetic rats. Nephrol. Dial. Transplant. 20, 1573-1581.

80. Epstein, M. (2001) Aldosterone as a determinant of cardiovascular and renal dysfunction. J. R. Soc. Med. 94, 378383.

81. Epstein, M. (2001) Aldosterone as a mediator of progressive renal disease: pathogenic and clinical implications. Am. J. Kidney Dis. 37, 677-688.

82. Rossing, K., Schjoedt, K., Smidt, U., Boomsma, R., and Parving, H.H. (2005) Beneficial effects of adding spironolactone to recommended antihypertensive treatment in diabetic nephropathy. Diabetes Care 28, $2106-2112$.

83. Han, S.Y., Kim, C.H., Kim, H.S., Jee, Y.H., Song, H.K., Lee, H.K., Han, K.H., Kim, H.K., Kang, Y.S., Han, Y.S., Kim, Y.S., and Cha, D.R. (2006) Spironolactone prevents diabetic nephropathy through an anti-inflammatory mechanism in type 2 diabetic rats. J. Am. Soc. Nephrol. 17, 1362-1372.

84. Takebayashi, K., Matsumoto, S., Aso, Y., and Inukai, T. (2006) Aldosterone blockade attenuates urinary chemoattractant protein-1 and oxidative stress in patients with type 2 diabetes complicated by diabetic nephropathy. $J$. Clin. Endocrinol. Metab., in press.

85. Xia, P., Inoguchi, T., Kern, T.S., Engerman, R.L., Oates, P.J., and King, G.L. (1994) Characterization of the mechanism for the chronic activation of diacylglycerol-protein kinase $\mathrm{C}$ pathway in diabetes and hypergalactosemia. Diabetes 43, 1122-1129.

86. Tuttle, K.R. and Anderson, P.W. (2003) A novel potential therapy for diabetic nephropathy and vascular complications: protein kinase C beta inhibition. Am. J. Kidney Dis. 42, 456-465.

87. Tuttle, K.R., Bakris, G.L., Toto, R.D., McGill, J.B., Hu, K., and Anderson, P.W. (2005) The effect of ruboxistaurin on nephropathy in type 2 diabetes. Diabetes Care 28, 2686-2690.

88. Han, J., Thompson, P., and Beutler, D. (1990) Dexamethasone and pentoxifylline inhibit endotoxin-induced cachectin/tumor necrosis factor synthesis at separate points in the signalling pathway. J. Exp. Med. 172, 393-394.

89. Doherty, G.M., Jensen, J.C., Alexander, H.R., Buresh, C.M., and Norton, J.A. (1991) Pentoxifylline suppression of tumor necrosis factor gene transcription. Surgery 110, 192-198.

90. Segal, R., Dayan, M., Zinger, H., and Mozes, E. (2001) Suppression of experimental systemic lupus erythematosus (SLE) in mice via TNF inhibition by an anti-TNF $\alpha$ monoclonal antibody and by pentoxifillyne. Lupus 10, 23-31.

91. Chen, Y.M., Ng, Y.Y., Lin, S.L., Chiang, W.C., Lan, H.Y., and Tsai, T.J. (2004) Pentoxifylline suppresses renal tumour necrosis factor- $\alpha$ and ameliorates experimental crescentic glomerulonephritis in rats. Nephrol. Dial. Transplant. 19, 1106-1115.

92. Chen, Y.M., Chien, C.T., Hu-Tsai, M.I., Wu, K.D., Tsai, C.C., Wu, M.S., and Tsai, T.J. (1999) Pentoxifylline attenuates experimental mesangial proliferative glomerulonephritis. Kidney Int. 56, 932-943. 
93. Lin, S.L., Chen, Y.M., Chien, C.T., Chiang, W.C., Tsai, C.C., and Tsai, T.J. (2002) Pentoxifylline attenuated the renal disease progression in rats with remnant kidney. J. Am. Soc. Nephrol. 13, 2916-2929.

94. DiPetrillo, K. and Gesek, F.A. (2004) Pentoxifylline ameliorates renal tumor necrosis factor expression, sodium retention, and renal hypertrophy in diabetic rats. Am. J. Nephrol. 24, 352-359.

95. Guerrero-Romero, F., Rodríguez-Morán, M., Paniagua-Sierra, J., García-Bulnes, G., Salas-Ramírez, M., and Amato, D. (1995) Pentoxifylline reduces proteinuria in insulin-dependent and non-dependent diabetic patients. Clin. Nephrol. 43, 116-121.

96. Navarro, J., Mora, C., Muros, M., Macía, M., and García, J. (2003) Effects of pentoxifylline administration on urinary $\mathrm{N}$-acetyl-beta-glucosaminidase excretion in type 2 diabetic patients: a short-term, prospective, randomised study. Am. J. Kidney Dis. 42, 264-270.

97. Harmankaya, O., Seber, S., and Yilmaz, M. (2003) Combination of pentoxifylline with angiotensin converting enzyme inhibitors produces an additional reduction in microalbuminuria in hypertensive type 2 diabetic patients. Ren. Fail. 25, 465-470.

98. Navarro, J.F., Mora, C., Muros, M., and García, J. (2005) Additive antiproteinuric effect of pentoxifylline in patients with type 2 diabetes under angiotensin II receptor blockade: a short-term, randomised, controlled trial. J. Am. Soc. Nephrol. 16, 2119-2126.

99. Chen, Y.M., Lin, S.L., Chiang, W.C., Wu, K.D., and Tsai, T.J. (2006) Pentoxifylline ameliorates proteinuria through suppression of renal monocyte chemoattractant protein-1 in patients with proteinuric primary glomerular diseases. Kidney Int. 69, 1410-1415.

100. Zimmet, P., Alberti, K.G., and Shaw, J. (2001) Global and societal implications of the diabetes epidemic. Nature 414, 782-787.

101. U.S. Renal Data System: USRDS 2004 Annual Data Report. In Atlas of End-Stage Renal Disease in the United States. National Institutes of Health, National Institute of Diabetes and Digestive and Kidney Diseases, Bethesda, MD.

102. Tuttle, K.R. (2005) Linking metabolism and immunology: diabetic nephropathy is an inflammatory disease. J. Am. Soc. Nephrol. 16, 1537-1538.

\section{This article should be cited as follows:}

Navarro, J.F. and Mora, C. (2006) Diabetes, inflammation, proinflammatory cytokines, and diabetic nephropathy. TheScientificWorldJOURNAL 6, 908-917. DOI 10.1100/tsw.2006.179. 

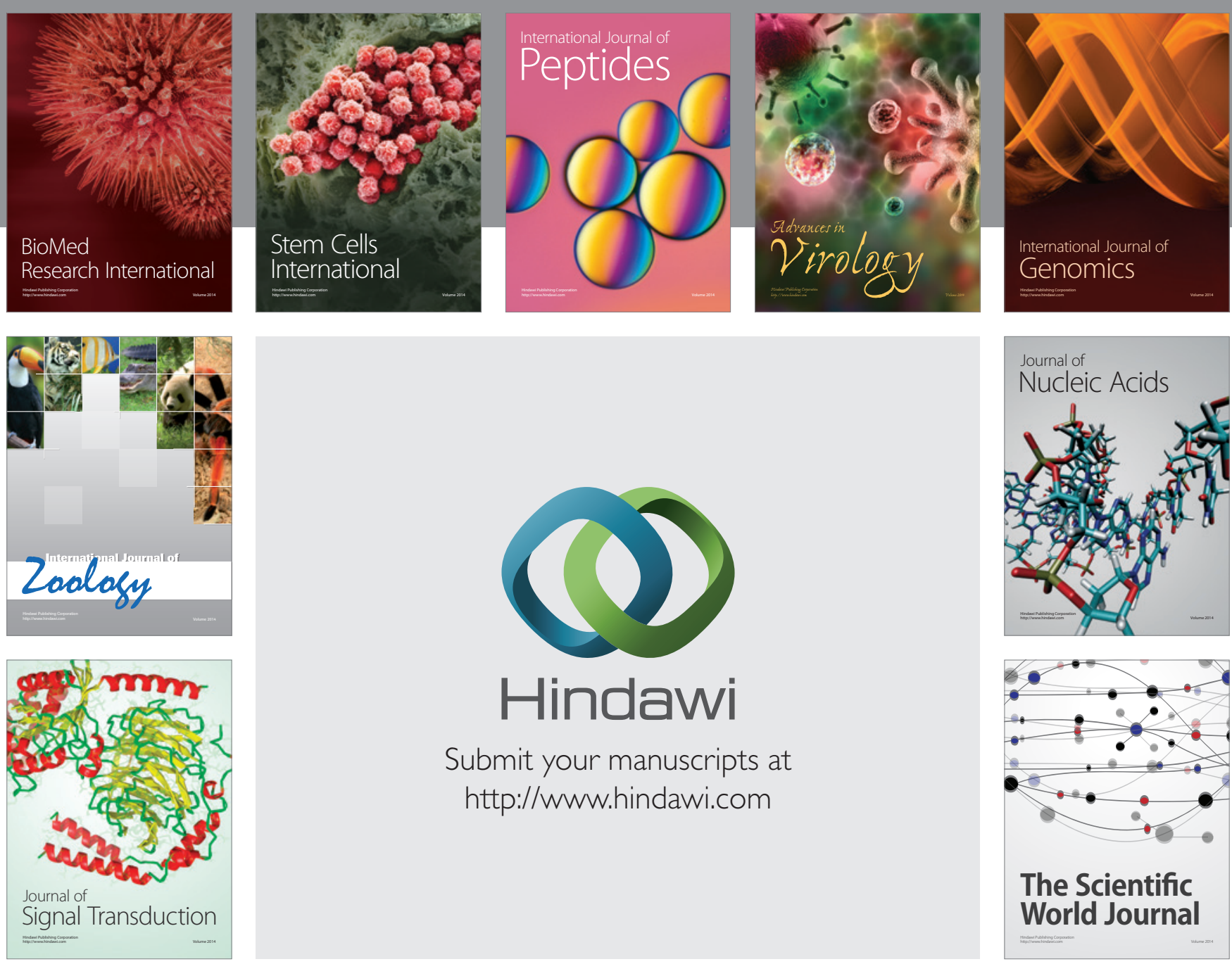

Submit your manuscripts at

http://www.hindawi.com
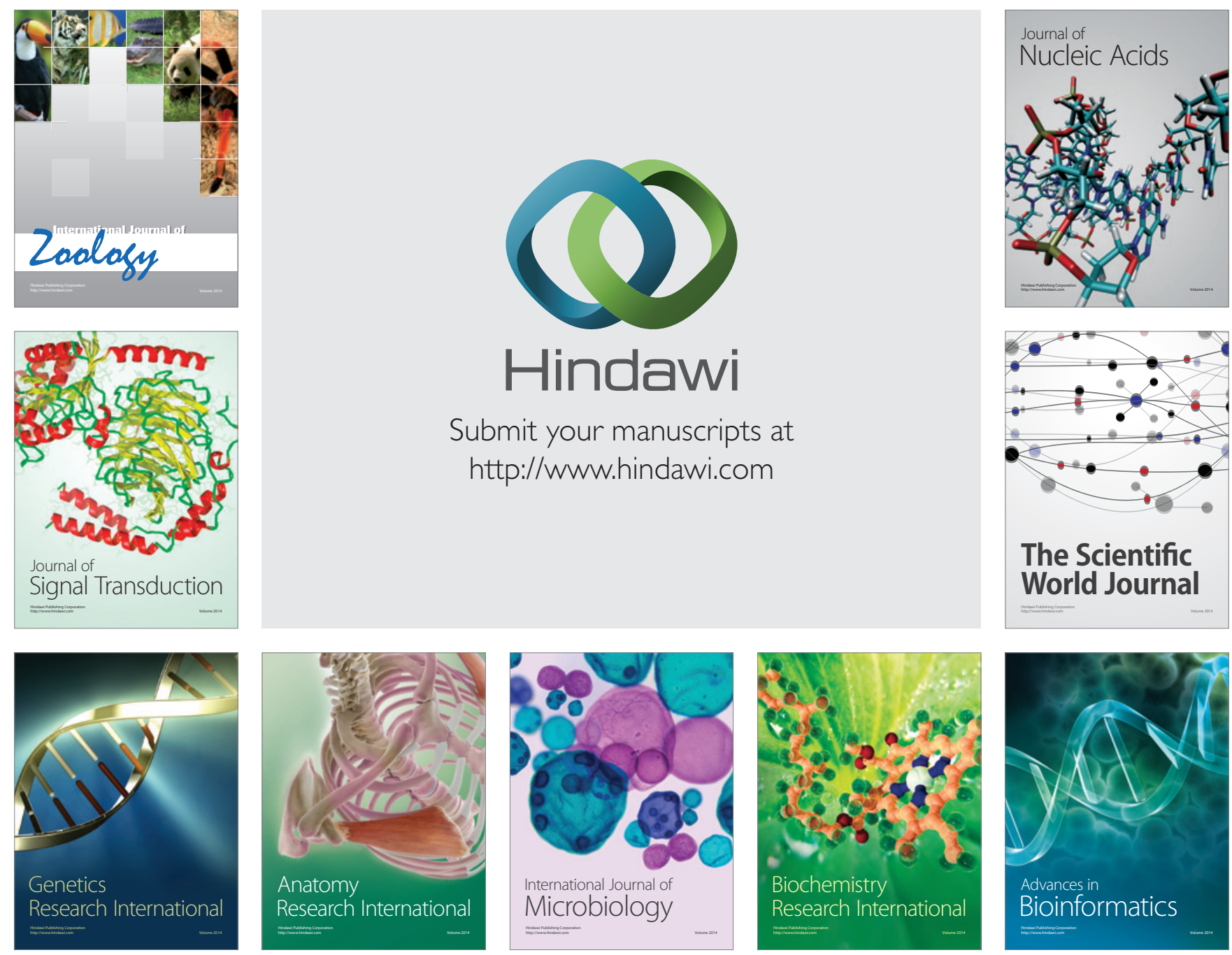

The Scientific World Journal
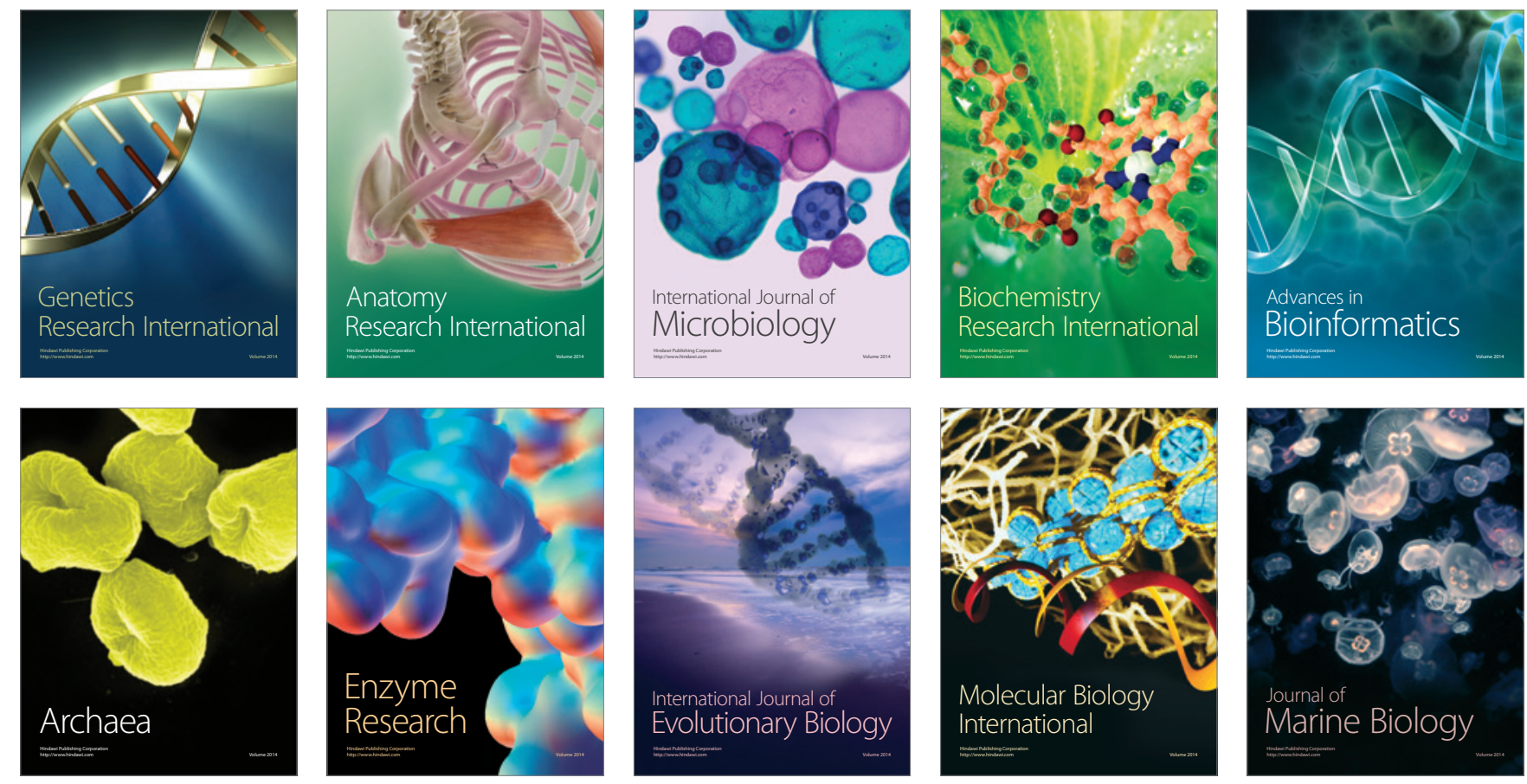